\title{
Research on Personnel Cultivation of Higher Engineering Education in China From Perspective of Problems and Solutions based on Training Process
}

\author{
Zhang Xue \\ School of Basic Medical Sciences, HeBei United University, Tangshan, China \\ Email: rosets@163.com \\ Received 2012
}

\begin{abstract}
In the past 10 years, higher engineering education has developed rapidly, and made the contribution to the modern engineering education system. However, cultivation of higher engineering education students meets new problems. Therefore, it is essential to deal with the problems to improve the quality of higher engineering education, and good advice should help engineering graduates more suitable to society.
\end{abstract}

Keywords: Higher Engineering Education; Personnel Cultivation; Problems and Solution; Training Process

\section{Introduction}

In recent years, with the rapid update of science and technology, engineers play an important role in promoting economic and social development. Therefore, the cultivation of engineering talents decides the level and speed of engineering technology, and has influence on the industrial competitiveness power. The higher engineering education occupies an important position in higher education structure, and becomes the main channel for cultivating engineers, thus supporting the development of engineering science and technology of the nation. Therefore, many countries are promoting engineering education reform and development, trying to cultivate the high-quality engineers to maintain the advantage in competition.

\section{The Definition, Characteristics and Status Quo}

\section{The Definition and Characteristics}

The higher engineering education is a specific education based on technological science, with the aim of cultivating engineer who can transfer science and technology into productivity [1]. It emphases on application in practice from theory, points at the capability of solving on-site engineering problems, focuses on team-spirit training.

Faced with the rapid and great changes of 21st century, American Engineering and Technology Certification Board made 11 assess standards for the new engineering education talents, including: (1) the capability of the application of mathematics, science and engineering knowledge, (2) the capability of design, laboratory analysis and data processing, (3) the capability of designing component, system or process as needed, (4) the comprehensive capacity of various training, (5) the capability to validate, guide and solve engineering problems, (6) the knowledge of profession and social responsibility, (7) the ability to express and communicate effectively, (8) the understanding of the impact of engineering problems on the global environment, (9) the ability of life-long learning, (10) the knowledge of today's problems, (11) the capacity of application of various techniques and modern engineering tools to solve practical problems. Thus, the $21^{\text {st }}$ century requires engineering graduates to have composite knowledge structure, comprehensive ability, and higher engineering quality [2].

\section{The Status Quo}

At present, the higher engineering education in China developed rapidly, making a lot of success. Firstly, in China, the education scale expands rapidly with engineering at university holding the largest share. In 2010, engineering students was about one-third of the total number of college students, the largest share of higher education. Secondly, education structure gets optimized. Professional master's degree based on application and practice has been affirmed and developed rapidly. Master of Engineering accounted for the largest share in 2010, with the total enrollment of 3.86 million people. Now we start the pilot of Doctor of Engineering Graduate Education [3]. Thirdly, the graduates have made significant achievement after graduation in the field of coal, metallurgy, petrochemical, manufacturing, electricity and transportation.

\section{Main Problems of the Cultivation}

Higher engineering education in China has made achievements, as scale expands, quality improves and efficiency increases. But compared with developed countries, there are still large gaps and many problems as below:

\section{Unclear Cultivating Objective}

China once followed the example of the Soviet system to set professional major, which focuses on the professional personnel target training [4]. After the reform, we found its limitation and began to explore the general education, the way of the United States. However, China's corporate research and development strength is relatively weak, and the engineer cannot be easily cultivated in the enterprise. In China's higher engineering education system, there is still a large controversy on how to train 
scientists or engineers. And it is a question to cultivate generalist or specialized personnel.

There is not enough coordination between degree, system and multi-level training requirements in engineering education. The training objective of the multi-level education and the division is not very clear, lack of characteristics. And there is still blind pursuit of high-level tendency. For example, some universities of technology are blind to the integrated direction, resulting in a single level and only one mode, unable to adapt to the diverse needs of the society.

\section{Old Teaching Content}

The problem exists in both traditional and emerging majors. The course content updates behind the times, and the theory is divorced from working practice. Many so-called new or revised materials is still in the original system with the content lack of knowledge that reflects the disciplinary development of cutting-edge new science, new technologies and new thinking.

\section{Lack of Practical Process}

In higher engineering education curriculum system, the theory classes occupy too large proportion, but the practice classes including hours of design, experiment, practice, trainee, graduate design share small parts. Too much emphasis on the theory of knowledge, while ignoring the practice of knowledge, results in theory not fully with practice. And practical lessons are just to test, review, consolidating to knowledge. Therefore, the graduates of Higher Engineering Education are mostly lack of practical ability, creative spirit, and practical problem-solving capability in integrated and complex project. Meanwhile, the drawback of communication and teamwork is demonstrated more prominent.

\section{Single Teaching Method}

Teaching method and model is usually an injection of knowledge education, which put too much emphasis on knowledge scheduled to teaching and acceptance of knowledge. The lack of interaction between teachers and students is the main problem, and it is difficult for students to actively participate in teaching activities. Traditional teaching methods and models are hard to help develop students' divergent, critical and creative thinking which is conducive to innovation ability. Besides, the above approach ignores the differences between different students, and it is not conducive to the personality development of students.

\section{Away from Enterprise Needs}

Engineering education which is not closely linked to the enterprises, and lack of forward-looking perspective on the market, has been revealed as a serious problem in the jobhunting market. For example, enterprises need a lot of engineering and technical personnel, but the graduates of Higher Engineering Education, cannot find the job which matches with their highly educated degree, due to the obsolete knowledge and little innovation.

\section{The Training Paths to Explore}

Under the present circumstances, Higher Engineering
Education in China must establish a reasonable education system and training mode in line with the requirements of the times, in order to meet the requirements of engineering and technical personnel in the context of globalization.

\section{Clear Training Objectives}

Higher engineering is a system, which includes professional education, undergraduate education, graduate education and postgraduate education. Engineering education at all levels should accurately locate their own training objectives. Higher professional education focuses on the cultivation of skilled personnel with the initial training of engineers. Undergraduate training completes the basic training of engineers. Graduate education cultivates senior specialists of the highest level. To be specific, master degree has higher requirements on the depth and breadth than the undergraduates and for doctoral students, the goal emphases on science and technology researchers and teaching staff.

Graduate education should be not limited to a single scholar model, but further adapt to society. The interdisciplinary Master of Engineering, Doctor of Engineering will gradually become an important form of graduate training. Higher Engineering Education mainly aims at training personnel who will work at first line of production, so it is important to build good foundation of knowledge and expertise, as well as to strengthen practical ability to work. Graduate as a complex talent with an interdisciplinary cross-professional degree will be welcomed by enterprises.

\section{Optimize the Teaching System}

Higher Education of Engineering has its own training objectives, academic settings, teaching content, teaching methods and management system. It is essential to adjust professional setting, expand professional caliber, broaden the basis of discipline, and change to adapt to the needs of the community project, which fully reflects the requirements of knowledge, ability and quality.

It is advisable to revise teaching plan according to the modern engineer training objectives, and to determine the proportion of various types of courses. It also should increase in the experimental design, trainee, internship and other practice hours and update teaching content by using the cutting-edge, advanced and practical new textbooks. Thus, it is indispensible to focus on interdisciplinary integration, broaden their knowledge, and enhance adaptability.

The re-application, re-practice, and re-solve the problem should be highlighted. Teaching method such as on-site teaching, case teaching, and participatory teaching should be used. To strengthen the application of modern teaching technologies and means, such as computer-aided teaching, online teaching, and to encourage students to identify and solve the problem in practice should be high lightened.

\section{Enhance the Project Training}

Higher Engineering Education requires engineers to lay a solid foundation of knowledge, with the actual ability to solve the engineering and technical problems. It is urgent to train qualified engineers for Chinese universities to strengthen the teaching of engineering practice, and modern engineering training for students. 
Engineering training is the real factory production process to train students to have engineering practice competencies, skills, and to develop the awareness of students' engineering process. China's universities should cooperate with industrial enterprises in the field of project, curriculum design, case studies, production practice and graduated design, closely combined with engineering practice.

Modern engineering training enable students to fully experience the innovation process, to develop students' awareness of creative thinking and innovation capability. Students operate by themselves, and to design, process, produce, learning not only innovative design in production, but also a comprehensive system throughout the training process.

\section{Acknowledgment}

Zhang Xue thanks the vice researcher Mr. Hu Qing-xi for recommendation of this conference and guiding degree papers on talents cultivation during study period, and thanks the vice researcher Mr. Liu Yun-qiu for guiding research on higher petroleum engineering education.

\section{REFERENCES}

Shi Ming-xian, "Engineering education reform for the 21st century" Beijing: China University Teaching, October 2002.

Zhao De-wu, "Stanford University practical educational philosophy and academic state-of-the-art scheme” Beijing: World Education, March 2005.

Zhu Gao-feng, "New century Chinese engineering education reform and development” Beijing: Higher Education of Engineering, January 2003.

Yu Li, "The history of higher education” Shanghai: East China NormalUniversity Press,pp.49, 1994. 